\title{
ASSESSMENT OF THE EFFECTOR ANTIBODIES AGAINST SCHISTOS- OMA MANSONI AND THEIR IMPACT ON MEFLOQUINE EFFICACY
}

By

\author{
SHAIMAA H. EL-SAYED ${ }^{1}$, HEBAT-ALLAH S. A. YOUSOF ${ }^{2}$, \\ and MONA M. M. KHATER ${ }^{\star}$
}

Departments of Medical Parasitology, Faculty of Medicine, Helwan University ${ }^{1}$, and Faculty of Medicine, Cairo University ${ }^{2}$, Cairo, Egypt

(*Correspondence: mona.m.khater@kasralainy.edu.eg; Phone: (+2) 01223949372)

\begin{abstract}
Host immune response against Schistosoma mansoni is a major contributor in the process of resistance or susceptibility to re-infection, as well as the therapeutic response towards different antischistosomal drugs. This study evaluated the role of IgG \&IgG4 as immune-logical marker of cure and their effect on anti-schistosomal mefloquine efficacy. Sixty Swiss albino mice were infected with Schistosoma cercaria and divided into four groups; non-infected, infected not treated, infected treated with praziquantel and infected treated with mefloquine. The effect of drugs was assessed parasitologically using Kato-Katz technique and immunologically by measuring the serum level of anti-Schistosoma IgG \& IgG4 subclass. The results showed $83.5 \%$ significant egg count reduction in MFQ-treated infected group. Also, serum anti-soluble egg antigen (SEA) total $\mathrm{IgG} \& \mathrm{IgG} 4$ subclass levels in MFQ treated group were significantly different from infected control group \& PZQ-treated infected group.
\end{abstract}

Key words: Schistosoma mansoni, Mefloquine, Kato-Katz, antischistosomal IgG \& IgG4

\section{Introduction}

Schistosomiasis is a widespread parasitic disease in tropical and sub-tropical areas. It occupies the second place in terms of socioeconomic and public health burden (Cardoso et al, 2013). Schistosoma mansoni (S. mansoni) is the most prevalent Schistosoma species in Egypt (Helmy et al, 2009). Studying hosts' immune response towards S. mansoni infection fills the gaps of knowledge about humoral immune responses against parasitic antigens within inhabitants of the endemic areas. The role of the cellular and humoral immune response in schistosomiasis mansoni was well characterized (Butterworth et al, 1988). Hypergammaglobulinemia, with consistently elevated total serum $\operatorname{IgG}$ and $\mathrm{IgE}$ concentration, is a common feature of this response in chronically untreated infected individuals (Ramírez et al, 1996). IgG4 antibody reactivity against specific schistosoma antigens have been involved in resistance or susceptibility to re-infection (Corrêa-Oliveira et al, 2000). Moreover, $\operatorname{IgE}$ and IgG4 isotypes, could serve as markers for picking up high risk patients susceptible to re-infection. Parasite-specific IgE are ac- companying resistance to the infection/reinfection, however, parasite-specific IgG4 is supposed to be a modulator of IgE effector responses (Black et al, 2010). IgG4 compete with $\operatorname{IgE}$ receptors thus preventing their binding to the high affinity receptor on eosinophil and hence minimize their activation and defensive role in induction of eosinophil-mediating killing of schistosomula (Khalife et al, 1989). Therefore, the expression of protective immune response depends on the favorable balance towards IgE production in the chronic infections and IgG4 produced in acute infection. In addition, IgG coated mast cells, up on stimulation with specific antigens, would stimulate production of protective antibodies in the entire IgG sub-classes and the release of eosinophils chemotactic factors (Khalife et al, 1986). The relative balance between these antibodies is a key feature in humoral immunity against schistosomes (Jiz et al, 2009).

Several medications are used in the treatment of schistosomiasis including praziquantel (PZQ), oxamniquine, metrifonate, antimonials, hycanthone and niridazole. 
Many evidences reported increased emergence of strains of $S$. mansoni resistant to PZQ (Zhang and Coultas, 2013). In recent years, antimalarial drug mefloquine (MFQ) exhibited potential effects against schistosomes (Xiao and Xue, 2012) with remarkable in vitro and in vivo activities against major Schistosoma species (El-Lakkany et al, 2011; Ingram et al, 2012; Zhang and Xiao, 2012; Abou-Shady et al, 2015; Abou-Shady et al, 2016). Numerous immunological tests using crude or purified egg and adult worm antigens have been developed in the last decades to detect anti-Schistosoma mansoni antibodies. Some of them have been recommended for post-treatment follow up.

The present study was designed to evaluate the role of specific anti-schistosomal IgG and $\mathrm{IgG} 4$ response in assessment of cure as well as for monitoring the efficacy of the antimalarial drug mefloquine ${ }^{\circledR}$ (MFQ).

\section{Materials and methods}

Significance of the study: To evaluate the role of specific anti-schistosomal IgG \& IgG4 response in assessment of cure and for monitoring efficacy of the antimalarial drug mefloquine.

Experimental animals and parasites: CD1 Swiss albino mice of both sexes $(n=60)$, aged 5-6 weeks were obtained from the experimental unit of Schistosome Biological Supply Program, Theodor Bilharz Research Institute (Giza, Egypt). The animals were kept under favorable temperature and humidity and were fed on standard commercial pelleted diet. Animals were infected individually through percutaneous route with 60 \pm 10 freshly shed Egyptian strain of $S$. mansoni cercariae from experimentally infected Biomphalaria alexandrina snails (Peters and Warren, 1969).

Tested drugs: MFQ (Mephaquin) tablets were purchased from Mepha Ltd., AeschBasel, Switzerland, and were given once as an oral suspension in $7 \%(\mathrm{v} / \mathrm{v})$ Tween-80 and $3 \%(\mathrm{v} / \mathrm{v})$ ethanol in a dosage of 400mg/Kg (Keiser et al, 2009).
PZQ (Distocide) tablets were purchased from EIPICO, El-Asher Men Ramadan, Egypt, and were crushed and given on two successive days as an oral suspension in $2 \%$ cremophore-E1 (Sigma-Aldrich Chemical Co., St. Louis, MO) in a dosage of 500 $\mathrm{mg} / \mathrm{kg} /$ day (Fallon and Doenhoff, 1994).

Both drugs were administrated to the infected mice 49 days post-infection (P.I.) using the esophageal tube.

Experimental design: The mice included in this study $(n=60)$ were divided into four groups; GI: non-infected negative control group, GII: infected non-treated control group, GIII: infected PZQ-treated animal group and GIV: infected MFQ-treated animal group.

Stool samples from all groups were collected 2 weeks after administration of the tested drugs for determination of the egg count in treated and control mice. Following stool collection, mice were decapitated and blood samples from all mice were collected for immunological study.

Kato-Katz technique (cellophane fecal thick smear) for egg counting in treated and control mice (Katz et al, 1972): Fecal pellets were collected from each mouse 9 weeks P.I. and processed for the presence and counting of $S$. mansoni eggs/gram of feces using the Kato-Katz technique. Briefly, a small amount of feces was placed on a scrap paper and a piece of nylon screen was pressed on top so as to sieve some of the feces through the screen to be accumulated on the top. A flat-sided spatula was scraped over the upper surface of the screen and the sieved feces were collected. A template was placed on the slide and the sieved feces were added with the spatula so that the hole in the template was completely filled. The spatula was passed over the filled template to remove excess feces from the edge of the hole. The template was removed cautiously and a cylinder of feces was left on the slide. The fecal sample was covered with cellophane green coverslip soaked with malachite green (3\% aqueous solution) to preserve and whit- 
en the material. The slide was inverted and the fecal sample was pressed firmly alongside the hydrophilic cellophane strip to spread uniformly. The slide was placed for one hour at room temperature on the bench with cellophane upwards to permit the evaporation of water while glycerol clears the feces before microscopic examination.

Three slides/mouse were made and exam ined under the light microscopy, the mean number of eggs within the three slides was calculated. The number of eggs/gram of feces was calculated by multiplying the mean number of eggs $\times 24$.

The percentage of egg output reduction in infected treated groups in comparison to infection control group was calculated according to the following equation:

$$
\frac{\text { No of eggs in infected non treated control }- \text { No. of eggs in treated }}{\text { Number of eggs in infected non treated control }} \times 100
$$

Immunological study: After mice decapitation, blood samples from all animals were collected in centrifuge tubes and were centrifuged at $3000 \mathrm{rpm}$ for $20 \mathrm{~min}$. Sera of animals were stored at $-20^{\circ} \mathrm{C}$ until used for immunological assay.

Determination of anti-SEA IgG and IgG4 subclass were measured using indirect ELISA (Engvall and Perlman, 1971). Briefly, ELISA microtiter plates were coated with $100 \mathrm{ul} / \mathrm{well}$ of $30 \mathrm{ug} / \mathrm{ml}$ of SEA. Sera were diluted 1:20 and anti-mouse $\mathrm{IgG}$ and $\mathrm{IgG} 4$ (Binding site, Birmingham, UK) were used at a dilution of 1:500. Absorbance was measured at $492 \mathrm{~nm}$ using ELISA reader (BioRad microplate reader, Richomond, Co.).

Statistical analysis: Results were analyzed using SPSS (version 20.0) software. Results were expressed in mean \pm standard error
(SE). All data were analyzed by using ANOVA test followed by Student's t-test at $95 \%$ confidence level. $P$-values $<0.05$ were considered as statistically significant.

Ethical considerations: The study was managed in accordance with the international valid guidelines for animal welfare and the animals were maintained under the appropriate conditions at Theodor Bilharz Research Institute.

\section{Results}

Parasitology: Assessment of S. mansoni egg count per gram of feces using Kato-Katz technique in MFQ-treated infected group was significantly different when compared to infected control group at $\mathrm{P}<0.05$, as the egg count reduction was $83.5 \%$, without statistical significance difference as compared to PZQ-treated infected group (Tab. 1).

Table 1: Schistosoma mansoni eggs per gram feces using Kato-Katz technique in mice infected treated with MFQ compared to PZQ-treated and infected control mice

\begin{tabular}{|l|c|c|c|}
\hline \multicolumn{2}{|c|}{ Animal group } & Number eggs/gm feces & Percentage of Reduction \\
\hline G II & Infected non-treated control & $307.33 \pm 17.09$ & - \\
\hline G III & Infected treated with PZQ & $39.17 \pm 5.67 *$ & $87 \%$ \\
\hline G IV & Infected treated with MFQ & $50.67 \pm 7.26 *$ & $83.5 \%$ \\
\hline
\end{tabular} Data as mean \pm SEM (n = 15 in each group). *Significant different from infected control (P < 0.05).

Immunology: Since MFQ treated mice demonstrated a significant reduction in egg output, antischistosomal humoral immune response induced in experimental mice following treatment was determined in the form of total $\mathrm{IgG} \& \mathrm{IgG} 4$, in response to SEA. The results showed that serum antiSEA total IgG level in mice infected treated with MFQ was significantly differed from infected control group at $\mathrm{P}<0.05$, without statistical significance difference when compared to PZQ treated infected group.

Meanwhile, assessment of serum anti-SEA IgG4 subclass level in mice infected and treated with MFQ was significantly different from infected control group and PZQ-treated infected group at $\mathrm{P}<0.05$ (Tab. 2). 
Table 2: Serum anti-SEA Total IgG \& IgG4 subclass levels in mice infected with S. mansoni and treated MFQ compared to PZQ

\begin{tabular}{|c|c|c|c|}
\hline \multicolumn{2}{|c|}{ Animal groups } & Total IgG & IgG4 \\
\hline G I & Non- infected control & $0.039 \pm 0.01$ & $0.151 \pm 0.04$ \\
\hline G II & Infected non-treated control & $1.657 \pm 0.252$ & $0.982 \pm 0.304$ \\
\hline G III & Infected treated with PZQ & $2.063 \pm 0.436^{*}$ & $1.382 \pm 0.249$ \\
\hline G IV & Infected treated with MFQ & $2.026 \pm 0.31^{*}$ & $0.676 \pm 0.158^{* \#}$ \\
\hline
\end{tabular}

* Significantl different from infected control $(\mathrm{P}<0.05)$, \#Significant different from infected treated with $\mathrm{PZQ}(\mathrm{P}<0.05)$

\section{Discussion}

Schistosomiasis is the third most overwhelming tropical disease in the world after malaria and intestinal helminthiasis. It represents a major cause of morbidity and mortality in the developing countries in Africa, South America, the Middle East, and Asia (WHO, 2010a). More than 240 million people who live in Africa are infected with schistosomiasis with an estimated 700 million people are at risk of infection where the disease is considered endemic (WHO, 2010 a, b; Santos et al, 2014). The prevalence of schistosomiasis increased with age and peaks between 15-20 years. On the other hand, there was no significant change found in the prevalence of disease in older adults, but the parasite burden decreases (Hagan and Gryeels, 1994). PZQ-based chemotherapy has attained some success in schistosomiasis control but reliance on a single drug is not adequate to reduce the long-term transmission and carries the risk of development of drug resistance (Bergquist et al, 2008). MFQ was found to be effective against various stages of different species of Schistosoma both in vitro and in vivo (Keiser et al, 2010; Xiao et al, 2011; Ingram et al, 2012). The accepted diagnostic standard of schistosomiasis mansoni is evidence of viable eggs in feces or tissue biopsies (De Vlas et al, 1997). In the present study, Schistosoma mansoni egg count per gram of feces using Kato-Katz technique was evaluated with significant egg count reduction in both MFQ-treated and PZQ-treated mice compared to infected control mice. The reported finding resulted from the effect of drugs on worm burden especially, the female worm burden. This result agreed with a randomized, exploratory open-label trial done on $S$. haematobium infected children and reported high cure rates of $61 \%$ and egg-reduction rates of $95 \%$ (Keiser et al, 2010a). Furthermore, administration of mefloquine in a dose of $400 \mathrm{mg} / \mathrm{kg}$ caused a statistical significant reduction in the number of mature female worms (El- Lakkany et al, 2011). Also, Abou-Shady et al, (2016) reported a significant reduction of tissue egg load with increased percentage of dead ova in the oogram pattern accompanied by significant reduction of the mature worm load. Serological assays have proven to be useful diagnostic tool by the detection of anti-schistosomal antibodies (Tsang et al, 1995). Some used isotypic assays can differentiate active from inactive infections (Grogan et al, 1996; Grogan et al, 1997; Webster et al, 1997). The relation between Schistosoma-specific IgE, eosinophils and resistance to reinfection has been detected in a variety of epidemiologic settings (Satti et al, 1996; Zhaosong et al, 1997; Jiz et al, 2009). Both high- and lowaffinity IgE receptors on eosinophils and B cells (or in soluble form), respectively, are linked with prevention of reinfection (Ganley-Leal et al, 2006; Mwinzi et al, 2009). Dissimilarly, susceptibility to reinfection has been related to $\operatorname{IgG} 4$, which might act as a blocking antibody, hindering the action of IgE (Satti et al, 1996; Zhaosong et al, 1997; Oliveira et al, 2012). Interestingly, Antischistosome IgG4 \& IgE responses matched their relative predisposition to reinfection (Grogan et al, 1996). To gain further insight on the effector function of anti-IgG4 on host immune responses and into the possible relationship between IgG4 subtype levels and response to MFQ therapy, the present study assessed the levels of total IgG \&IgG4 in MFQ-treated mice and compared them with 
that of infected non-treated and PZQ-treated animals. The present results revealed significantly higher IgG response to SEA in MFQtreated mice, in comparison with both untreated and treated with PZQ groups. Similarly, IgG were shown to influence the efficacy of the drug in plasma cell-suppressed mice as well as they were found on the tegument of worms in immunocompetent mice post treatment by PZQ (Brindley' And Sher, 1987). Allam (2009) declared that Curcumin treatment of murine schistosomiasis mansoni enhanced the humoral immune response by increased serum IgG against both SWAP and SEA. It has been documented that IgG antibodies response plays a crucial rule in protection against experimental and human schistosomiasis (Hoffmann et al, 1999; Jankovic et al, 1999). Besides, Marques et al (2008) detected high levels of IgG with a protection of $57 \%$ against infection and hepatic granuloma significantly declined in number when mice vaccinated with recombinant P44 (fructose1, 6 bisphosphate aldolase antigen). Levels of IgG4 to SEA were significantly higher in sera from infected non-treated mice and relatively higher in PZQ treated group as compared to MFQtreated mice. This observation could explain how the well-known property of mefloquine in eliminating juvenile stages of schistosoma, and consequently ability of resisting reinfection, is working. These results agreed with previously reported finding following treatment of human cases infected with $S$. mansoni (Walter et al, 2006; De Moira et al, 2010). They found decrease in the levels of Schistosoma-specific IgG4, but, Schistosoma -specific $\operatorname{IgE}$ was maintained at pretreatment levels or increases and stated that, certain $S$. mansoni adult worm-associated tegumentalallergen-like (TAL) proteins have been characterized as important potential targets of protective IgE and reinfection-associated IgG4. Thus, treatment with MFQ caused decrease in the levels of anti-SEA IgG4 which was correlated to decreased intensity of infection, as measured by reduced number of shed eggs. This suggested that the resistance to reinfection could be influenced by type and amount of antibodies produced by the antigens released from eggs. Long-standing effect of immunological change needs more investigation using specific stage antigens to establish the nature and development of acquired immunity.

\section{Conclusion}

The results showed that the serum level of antischistosomal antibodies class provoked against the parasite antigens influences prognosis and treated schistosomiasis outcome.

Contribution of each author: All manuscript authors contributed to every activity of it; idea of paper, study design, collection of materials, methodology, writing the paper and revising it.

Conflict of interest: The authors declare that they neither have competing interests nor received financial support.

\section{References}

Abou-Shady, OM, Mohammed, SS, Attia, SS, Yusuf, HAS, Helmy, DO, 2015: In vitro Effect of Mefloquine on Adult Schistosoma mansoni. Res. J. Parasitol. 10, 3:111-9.

Abou-Shady, OM, Mohammed, SS, Attia, SS, Yusuf, HAS, Helmy, DO, 2016: Therapeutic effect of mefloquine on Schistosoma mansoni in experimental infection in mice. J. Parasit. Dis. 40, 2:259-67.

Allam, G, 2009: Immunomodulatory effects of curcumin treatment on murine schistosomiasis mansoni. Immunobiol. 214:712-27.

Bergquist, R, Utzinger, J, McManus, DP, 2008: Trick or treat: the role of vaccines in integrated schistosomiasis control. PLoS Negl. Trop. Dis. 2, 6:e244.

Black, CL, Muok, EM, Mwinzi, PN, 2010: Increases in levels of schistosome-specific immunoglobulin E and CD23 (+) B cells in a cohort of Kenyan children undergoing repeated treatment and reinfection with Schistosoma mansoni. J. Infect. Dis. 202:399-405.

Brindley, PJ, Sher, A, 1987: The chemotherapeutic effect of praziquantel against Schistosoma mansoni is dependent on host antibody response. J. Immunol. 139:215-20.

Butterworth, AE, Dunne, D, Fulford, A, Capron, M, Khalife, J, et al, 1988: Immunity in 
human Schistosomiasis mansoni: Cross reactive IgM \& IgG2 anti-carbohydrate antibodies block the expression of immunity in young children. Biochimie. 70:1053-63.

Cardoso, LS, Barreto Ade, S, Fernandes, JS, Oliveira, RR, de Souza Rda, P, et al, 2013: Impaired lymphocyte profile in schistosomiasis patients with periportal fibrosis. Clin. Dev. Immunol. 7:106-47.

Corrêa-Oliveira, R, Rodrigues Caldas, I, Martins-Filho, O.A, Carvalho Queiroz, C, Lambertucci, J.R, et al, 2000: Analysis of the effects of treatment of human Schistosoma mansoni infection on the immune response of patients from endemic areas. Acta Trop. 77:141-6.

De Moira, AP, Fulford, AJ, Kabatereine NB, Ouma, JH, Booth, M, et al, 2010: Analysis of complex patterns of human exposure and immunity to Schistosomiasis mansoni: the influence of age, sex, ethnicity and IgE. PLoS Negl. Trop. Dis. 4: e820.

De Vlas, SJ, Engels, D, Rabello, AL, Oostburg, BF, van Lieshout, L, et al, 1997: Validation of a chart to estimate true Schistosoma mansoni prevalences from simple egg counts. Parasitol. 114:113-21.

El-Lakkany, NM, el-Din, SHS, Sabra, AA, Hammam, OA, 2011: Pharmacodynamics of mefloquine and praziquantel combination therapy in mice harbouring juvenile and adult Schistosoma mansoni. Mem. Inst. Oswaldo Cruz 106: 814-22.

Engvall, E, Perlman, P, 1970: Enzyme linked immunosorbent assay (ELISA) Quantitative assay of immunoglobulin. Immunochem. 8:871-4. Fallon, PG, Doenhoff, MJ, 1994: Drug-resistant schistosomiasis: resistance to praziquantel and oxamniquine induced in Schistosoma mansoni in mice is drug specific. Am. J. Trop. Med. Hyg. 51:83-8.

Ganley-Leal, LM, Mwinzi, PNM, Cetre-Sossah, CB, Andove, J, Hightower, AW, et al. 2006: Higher percentages of circulating mast cell precursors correlate with susceptibility to reinfection with Schistosoma mansoni. Am. J. Trop. Med. Hyg. 75:1053-7.

Grogan, JL, Kremsner, PG, van Dam, GJ, Deelder, AM, Yazdanbakhsh, M, 1997: Antischistosome $\mathrm{IgG} 4$ and $\mathrm{IgE}$ at 2 years after chemotherapy: infected versus uninfected individuals. J. Infect. Dis. 176:1344-50.

Grogan, JL, Kremsner, PG, van Dam, GJ, Metzger, W, Mordmüller, B, et al, 1996: Anti- schistosome $\operatorname{IgG} 4$ and $\operatorname{IgE}$ responses are affected differentially by chemotherapy in children versus adults. J. Infect. Dis. 173:1242-7.

Hagan, P, Gryeels, B, 1994: Schistosomiasis research and the European Community. Trop. Geogr. Med. 46:256-9.

Helmy, M, Mahmoud, S, Fahmy, Z, 2009: Schistosoma mansoni: effect of dietary zinc supplement on egg granuloma in Swiss mice treated with praziquantel. Exp. Parasitol. 122:310-7.

Hoffmann, KF, James, SL, Cheever, AW, Wynn, TA, 1999: Studies with double cytokinees-deficient mice reveal that highly polarized Th1 \& Th2 type cytokine and antibody responses contribute equally to vaccine-induced immunity to Schistosoma mansoni. J. Immunol. 163: 927-38.

Ingram, K, Ellis, W, Keiser, J, 2012: Anti-schistosomal activities of mefloquine-related arylmethanols. Antimicrob. Agents Chemother. 56, 3:207-15.

Jankovic, D, Wynn, TA, Kullberg, MC, Hieny, S, Caspar, P, et al, 1999: Optimal vaccination against Schistosoma mansoni requires the induction of both B cell-and IFN- $\gamma$-dependent effector mechanisms. J. Immunol. 162, 1:34551.

Jiz, M, Friedman, JF, Leenstra, T, Jarilla, B, Pablo, A, et al, 2009: Immunoglobulin E (IgE) responses to paramyosin predict resistance to reinfection with Schistosoma japonicum and are attenuated by IgG4. Infect. Immun. 77:2051-8.

Katz, N, Chaves, A, Pellegrino, JP, 1972: A simple device for quantitative stool thick-smear technique in schistosomiasis mansoni. Rev. Inst. Med. Trop. 14:397-400.

Keiser, J, Chollet, J, Xiao, SH, Mei, JY, Jiao, PY, Utzinger, J, 2009: Mefloquine: An amino alcohol with promising antischistosomal properties in mice. PLoS Negl. Trop. Dis. 3, 1:1-11.

Keiser, J, Vargas, M, Doenhoff, MJ, 2010: Activity of artemether and mefloquine against juvenile and adult Schistosoma mansoni in athymic and immunocompetent NMRI Mice. Am. J. Trop. Med. Hyg. 82, 1:112-4.

Khalife, J, Capron, M, Capron, A, Grzych, J M, Butterworth, AE, et al, 1986: Immunity in human schistosomiasis regulation of protective immune mechanisms by IgM blocking antibodies. J. Exp. Med. 164:1626-40.

Khalife, J, Dunne, DW, Richardson, BA, Mazza, G, Thorne, KJI, et al, 1989: Functional role of IgG subclasses in eosinophil mediated 
killing of schistosomula of Schistosoma mansoni. J. Immunol. 142:4422-7.

Marques, HH, Zouain, CS, Torres, CB, Oliveira, JS, Alves, JB, Goes, AM, 2008: Protective effect and granuloma down-modulation promoted by RP44 antigen a fructose 1, 6 bisphosphate aldolase of Schistosoma mansoni. Immunobiol. 213, 5:437-46.

Mwinzi, PNM, Ganley-Leal, L, Black, CL, Secor, WE, Karanja, DMS \& Colley DG, 2009: Circulating CD23+ B cell subset correlates with development of resistance to Schistosoma mansoni reinfection in occupationally exposed, multiply treated adults. J. Infect. Dis. 199:272-9.

Oliveira, RR, Figueiredo, JP, Cardoso, LS, Jabar, RL, Souza, RP, et al. 2012: Factors associated with resistance to Schistosoma mansoni infection in an endemic area of Bahia, Brazil. Am. J. Trop. Med. Hyg. 86:296-305.

Peters, AP, Warren, KS, 1969: A rapid method of infecting mice \& other laboratory animals with Schistosoma mansoni subcutaneous injection. J. Parasitol. 55:558-63.

Ramirez, BL, Kurtis, JD, Wiest, PM, Arias, P, Aligui, F, et al, 1996: Paramyosin: A Candidate Vaccine Antigen Schistosoma japonicum. Parasite Immunol. 18: 49-52.

Santos, J, Gouveia, MJ, Vale, N, de Lurdes Delgado M, et al, 2014: Urinary estrogen metabolites and self-reported infertility in women infected with Schistosoma haematobium. PLoS One. 9, 5: e96774.

Satti, MZ, Lind, P, Vennervald, BJ, Sulaiman, SM, Daffalla, AA, et al, 1996: Specific immunoglobulin measurements related to exposure and resistance to Schistosoma mansoni infection in Sudanese canal cleaners. Clin. Exp. Immunol. 106:45-54.

Tsang, VC, Hillyer, GV, Noh, J, Vivas-Gonz alez, BE, Ahn, LH, et al, 1997: Geographic clustering and seroprevalence of schistosomiasis in Puerto Rico. Am. J. Trop. Med. Hyg. 56:107-12.
Walter, K, Fulford, AJ, McBeath, R, Joseph S, Jones FM, et al. 2006: Increased human IgE induced by killing Schistosoma mansoni in vivo is associated with pretreatment Th2 cytokine responsiveness to worm antigens. J. Immunol. 177:5490-8.

Webster, M, Fallon, PG, Fulford, AJ, Butter worth, AE, Ouma, JH, et al, 1997: IgG4 and IgE responses to Schistosoma mansoni adult worms after treatment. J. Infect Dis. 175:493-4.

WHO, 2010a: Schistosomiasis, Fact Sheet No. 115. Available at http://www.who.int/ mediacentre/ factsheets/fs 115/en/. Accessed: Oct 5, 2010. WHO, 2010b: Weekly epidemiological record. 85:157-64.Available at http://www.who.int/wer. Accessed: Sept. 27,2010.

Xiao, SH, Mei, JY, Jiao, PY, 2011: Effect of mefloquine administered orally at single, multiple, or combined with artemether, artesunate, or praziquantel in treatment of mice infected with Schistosoma japonicum. Parasitol. Res. 108, 2: 399-406.

Xiao, SH, Xue, J, 2012: Study progress on mefloquine against schistosomes and other helminthes. "Zhongguo ji sheng chong xue yu ji sheng chong bing za zhi". Chinese J. Parasitol. Parasit Dis. 30, 2:131-8.

Zhang, CW, Xiao, SH, 2012: Histopathological changes of juvenile Schistosoma japonicum harbored in mice treated orally with mefloquine at a smaller single dose. Parasitol. Res. 110, 6:22818.

Zhang, S, Coultas, KA, 2013: Identification of plumbagin and sanguinarine as effective chemotherapeutic agents for treatment of schistosomiasis. Drugs Drug Resist. Int. J. Parasitol. 3:28-34.

Zhaosong, Z, Haiwei, W, Suchen, C, Hu, L, Xie, Z, et al, 1997: Association between $\operatorname{IgE}$ antibody against soluble egg antigen and resistance to reinfection with Schistosoma japonicum. Trans. R. Soc. Trop. Med. Hyg. 91:606-8. 